\title{
CityLab at Boston University - Thirty Years of Innovation and Partnerships
}

\author{
Donald DeRosa ${ }^{1,2}$, Carl Franzblau', Constance Phillips ${ }^{3}$, Carla Romney ${ }^{1}$ \\ ${ }^{1}$ Boston University School of Medicine, Boston, Massachusetts; '2Boston University Wheelock College of Education and Human Development, Boston, \\ Massachusetts; and ${ }^{3}$ Boston University School of Medicine (Ret.), Boston, Massachusetts \\ Keywords: STEM Education, STEM Outreach, Mobile Science Laboratory, Biotechnology Education, Biomedical Science Education, Pre-College Enrichment \\ Program, Hands-On Laboratory Experience, Student-Centered Teaching \\ Publication Date: August 10, 2020
}

DOI: https://doi.org/10.15695/jstem/v3i2.02

\begin{abstract}
Boston University's (BU) CityLab program was created in 1991 as a partnership between faculty members of BU's School of Medicine and School of Education in response to the first call for proposals under the Science Education Partnership Awards initiative of the National Institutes of Health. CityLab's founders recognized the need for CityLab, a centrally-located facility for pre-college teachers and students to explore the burgeoning world of biotechnology. The mission has always been to share the excitement of science with students and teachers by engaging them in hands-on laboratory experiences, thereby fostering the development of a robust pool of scientists and physicians and a scientifically-literate populace. In order to reach more schools, particularly those that could not come to CityLab's facility in Boston, the CityLab team pioneered the mobile science laboratory concept with the launch of its MobileLab in 1998. Both CityLab and MobileLab have been replicated in the U.S. and abroad. CityLab has sustained itself because it has benefited from stable leadership, built and disseminated models for hands-on STEM education, embraced innovation by creating new programs to serve additional populations, and developed diverse funding streams. The CityLab program has been remarkable in its outreach, success, and longevity.
\end{abstract}

\section{INTRODUCTION}

Educational outreach programs play an important role in exposing students to STEM (science, technology, engineering, and mathematics) by complementing and augmenting conventional classroom learning and engaging young people so that they continue to pursue studies in these fields. Most STEM educational outreach programs are offered by academic or research institutions, museums, and science centers, but some companies and professional organizations also have developed programs to inspire youth to seek careers in STEM. One challenge that nearly all outreach programs face is how to satisfy two seemingly competing goals- the strong desire to make these programs available to as many people as possible at the lowest possible cost and the urgent need for funding to sustain successful existing programs and create new ones. Since its inception in 1991, CityLab at Boston University (BU) has flourished due to its unwavering commitment to programmatic innovation, pursuit of multiple streams of funding, and creation of an environment that has led to stable leadership and longlasting relationships with staff. CityLab has been remarkable in terms of the breadth of its outreach and longevity.

CityLab, a biotechnology learning laboratory program for pre-college students and their teachers, emanated from earlier efforts to build the local biotechnology workforce through exposing pre-college educators to state-of-the-art molecular biology labs and pedagogy. CityLab has held fast to its founding mission: to share the excitement of science with students and their teachers by engaging them in handson biomedical science laboratory experiences.

\section{HISTORY OF CITYLAB}

The inspiration for the CityLab program at Boston University School of Medicine (BUSM) and School of Education (SED, now known as Boston University Wheelock College of Education and Human Development) had its origin in the late 1980s, several years before the National Institutes of Health $(\mathrm{NIH})$ initiated the Science Education Partnership Award (SEPA) program at the National Center for Research Resources (NCRR). At that time, BUSM partnered with BU's Metropolitan College (MET) to offer a bachelor's degree in Biomedical Laboratory and Clinical Sciences (BLCS) that prepared students to work in the blossoming local biotechnology community. BUSM offered 
the STEM coursework and lab components while MET, the academic unit at BU that caters to working adults and non-traditional students, offered the remaining liberal arts coursework. The initial student recruitment plan was based upon enrolling students directly from local high schools as well as from companies and research institutions in Boston and its environs. The BLCS program director visited dozens of high school science classes to recruit students for the program by explaining how it would prepare them for personally and professionally rewarding careers in the emerging biotechnology industry. Despite this personalized contact, it became apparent that directly recruiting BLCS students from area high schools would not yield sufficient enrollment to ensure the program's on-going financial viability.

Although biotechnology was burgeoning in the Boston area, there was little to no awareness of this field and the career opportunities it offered within areas of significant socioeconomic and educational disadvantage. One possible means to address the lack of awareness depended on engaging teachers and their students to explore the fundamentals of biotechnology and experience the wonder and excitement of laboratory sciences in their own high school classrooms. Students who had positive biomedical science learning experiences during their pre-college years might be more likely to consider pursuing further education and a career in this field. Of course, these formative experiences depended on having classroom teachers who were able to spark an interest in scientific inquiry and laboratory experimentation. It quickly became apparent that most high school science teachers, in Boston and elsewhere, lacked the scientific and pedagogical content knowledge, laboratory experience, and resources to teach biotechnology effectively in their own classrooms (National Research Council, 2006, 2007; Rutherford et al., 1989, and Watanabe, 2011). This insight led to the submission of a grant application to the Bay State Skills Corporation to fund weekend biotechnology professional development workshops for Boston area science teachers.

Partnering with teachers in mutually supportive collaborations was essential to the growth of the BLCS program and became a touchstone for CityLab once it was established. By building teachers' biotechnology laboratory skills and pedagogical expertise so that they could successfully incorporate modern biology into their classes, CityLab's leaders hoped to build a base for recruiting students for the BLCS program. To support this program, the CityLab team secured grants from the U.S. Department of Education Fund for the Improvement of Post-Secondary Education (FIPSE) and the Dwight D. Eisenhower Mathematics and Science Education Program (Eisenhower), the largest Federal program for training elementary and secondary teachers in math and science. These grants provided funding to design and conduct workshops on biotechnology laboratory techniques and associated pedagogical strategies that teachers could use to engage their students in laboratorybased science and spark their interest in attendant career opportunities, including the BLCS program. This "winwin" situation provided a means to recruit diverse cohorts of students into the BLCS program while offering a path to sustainable employment in the biotechnology industry.

While the workshops were well received and addressed teachers' needs for pedagogical and scientific content knowledge to accompany the new laboratory skills and techniques, teachers still lacked funding for the required laboratory equipment and supplies, had insufficient or no dedicated lab space, and did not have adequate time to provide their students with authentic and compelling laboratory-based biotechnology learning experiences (National Research Council, 2006, 2007; Rutherford et al., 1989, and Watanabe, 2011). Recognizing these challenges to improving pre-college biomedical science education, the workshop leaders had an epiphany during one of the sessions in 1990: what was needed was a central learning laboratory at BU in Boston so that teachers could come, with their students, to a professionally-outfitted facility (personal communications). This was the genesis of CityLab, a biotechnology learning laboratory designed to inspire precollege students and teachers in the greater Boston area.

The first challenge that the team faced was finding funding to create this new central resource, CityLab. Neither BUSM nor SED had resources to fund CityLab's startup costs, so initial support had to come from outside of BU. At that time, Dr. Sidney McNairy, with the support of Dr. Judith Vaitukaitis, the Director of NCRR, announced the creation of SEPA, a program to stimulate pre-college students to pursue careers in the life sciences including biotechnology through scientist-educator partnerships. In 1990-1991, BUSM and SED partnered to write BU's first SEPA grant application, which sought funds for CityLab, conceptualized therein as a centralized laboratory resource and physical space at BUSM where middle and high school teachers could bring their students, engage in biomedical science experiments, and gain an appreciation for scientific inquiry. The grant application and the materials that were developed subsequently emphasized both developing scientific ways of thinking and immersing students in an authentic biotechnology lab setting so that laboratory techniques served as tools to generate data for answering a question or solving a problem.

CityLab's first SEPA grant was awarded in 1991; inspired by the SEPA vision, the grant supported the immediate hiring of an educator and biochemist to forge the educatorscientist partnership model that would become the backbone of CityLab and an enduring contributor to its success. As a team and with extensive input from teachers who attended the professional development workshops, CityLab 
developed its laboratory-centric curriculum to surmount four challenges that often impeded teachers' implementation of these experiences with their students: unfamiliar science content, limited pedagogy for teaching laboratory science, inadequate coaching and mentoring, and insufficient access to essential resources (National Research Council, 2006, 2007; Rutherford et al., 1989, Watanabe, 2011).

Many teachers, particularly in the 1990s and early 2000s, had limited experience with molecular biology and biotechnology science content and laboratory skills. While the teacher workshops held on-site at BUSM were helpful and allowed teachers to deepen their content knowledge and develop laboratory skills, CityLab's leaders found that teachers frequently needed significant additional support to prepare and teach the laboratory-based investigations in their own classrooms. Teachers gained confidence and acquired practical skills while observing and/or co-teaching their students with the CityLab staff, who were very well versed in leading the laboratory investigations with students across a wide range of grade and developmental levels. Visits to CityLab provided key coaching and mentoring opportunities for teachers to advance their knowledge and skills while working with their own students in a supportive environment. Many teachers then began to implement biotechnology lab experiences in their own classrooms.

At a practical level, it is often not financially possible or time effective for schools to own laboratory equipment and prepare reagents that support molecular biology investigations that are done only a few times per year. A centrally-located laboratory with a staff of science educators that serves many schools and teachers, such as CityLab, can maintain the equipment and prepare fresh reagents to optimize results and student success. CityLab became an integral part of the greater Boston science education ecosystem because it placed teachers and their students at the heart of its programming and filled a crucial niche in building the talent pipeline for the biotechnology workforce.

Over the past thirty years, CityLab has developed many programs to support its overall mission of providing opportunities in biotechnology to underserved populations in the greater Boston area. To illustrate the breadth of CityLab's activities and major achievements, the next section traces many of the innovative programs that have been created after receipt of the first SEPA grant.

Teacher Professional Development Workshops. This is the longest-running component of CityLab, predating its formal inception. CityLab has conducted weekly workshops during the summer to introduce teachers to laboratory procedures and equipment as well as the scientific principles that govern their use. These workshops model the inquiry-based hands-on pedagogy that is employed in the CityLab curriculum supplements. CityLab staff members have presented regularly at professional conferences such as the National Science Teaching Association, National Association of Biology Teachers, NIH SciEd conference, and the Mobile Laboratory Coalition as well as at many regional STEM conferences. CityLab has been invited to institutions across the United States and abroad to share its programs and curricula. CityLab has provided professional development for more than 2,000 teachers. Thousands more have been reached through programs modeled on CityLab and/or its MobileLab. After their experiences with CityLab's materials, teachers at many levels, from middle school to graduate school, have been instrumental in spreading the CityLab vision.

CityLab Daily Visits. Upon receipt of the first SEPA grant in September 1991, CityLab developed a series of day-long biotechnology laboratory experiences that were designed to be carried out at CityLab. The curriculum supplements were developed as mysteries with focal guiding questions that motivated students to understand how laboratory investigations using techniques such as DNA fingerprinting, polymerase chain reaction, DNA and protein electrophoresis, protein quantitation, and ELISA could advance their knowledge and help to solve the mysteries (DeRosa and Wolfe, 1993a, 1993b, 1993c, 1994, 1999; Sherr et al., 1993). These curriculum supplements were structured with pre-lab and post-lab components that teachers taught to their students in their own classrooms. Initially, teachers were required to attend CityLab's teacher professional development workshops prior to bringing their classes to CityLab in order to foster the growth of personal connections and scientist-educator partnerships between CityLab staff and teachers. Over time, this requirement was relaxed when it became clear that having teachers experience and co-teach the laboratory-based curriculum supplements at CityLab with their students provided superior pedagogical and content knowledge that was unattainable in teacheronly workshops. Eventually, the requirement for attendance at the workshops as a prerequisite for bringing students to CityLab was removed because many teachers who wanted to incorporate CityLab experiences into their classes did not have time to attend the workshops. Removing the workshop attendance prerequisite removed an obstacle for teacher and student participation and allowed the program to grow so that there was a year-long waiting list to bring a class to CityLab. To date, more than 70,000 students, along with their teachers, have participated in a CityLab daily visit. These visits were augmented by teacher-led post-lab experiences back in their own classrooms. CityLab's curriculum supplement model that uses engaging biomedical mysteries or challenges in a pre-lab, lab, and post-lab sequence, remains a backbone of CityLab's programming to this day. 
SummerLab. In the early years, students who came to CityLab with their teachers frequently asked for additional out-ofschool opportunities to perform laboratory experiments. In response to this attendee-driven demand, CityLab created a week-long biotechnology summer immersion program called SummerLab in 1996. SummerLab began as a program for 24 students in grades 9 to 12 in a single session that focused on understanding the central dogma through laboratory experiences using bacterial transformation (Topalian et al., 1995) and protein purification. In 2014, SummerLab added a second week-long program that explores the design and role of clinical trials. SummerLab has expanded to four one-week sessions per summer with approximately 150 students from Boston and around the world. More than 1,500 students have participated to date. In addition, the majority of students' families and friends have shared in the experience of SummerLab by attending the poster session at the conclusion of each week's program and learning from the SummerLab participants as they explain their work.

CityLab Scholars. Since 1998, students who completed the SummerLab program and lived within commuting distance of BUSM were invited to deepen their knowledge and repertoire of molecular biology concepts, skills, and lab techniques through the CityLab Scholars program, a monthly series of after-school laboratory explorations during the school year. The Scholars program meetings have also served as the first pilot testing venue for many of CityLab's curriculum supplements, thereby ensuring that student input and feedback have been integrated into newly-developed materials before they are used by teachers. This program has engaged more than 150 students to date. More recently, CityLab's leaders created a new pathway for Scholars participants to contribute to SummerLab in subsequent years by returning as near-peer lab assistants. The lab assistants are paid members of the SummerLab staff and relish the opportunity to demonstrate and perfect their lab and communication skills.

BU MobileLab. In the mid-1990s, CityLab's leaders again grappled with the challenge of bringing a biotechnology lab to students and teachers at their schools. As costs increased for schools to secure buses for trips to CityLab, there was a reduced demand for the programs offered on-site at BUSM, especially from teachers in resource-constrained schools. To address their needs, a new solution was needed - a laboratory on wheels that would enable CityLab to bring hands-on biotechnology laboratory experiences to students and teachers at their schools. The BU MobileLab, which debuted in 1998, is forty-foot bus that contains a fully-equipped laboratory that accommodates 24 students and two instructors doing wet lab investigations in molecular biology. With the addition of the BU MobileLab, CityLab extended its reach to students and teachers at any school within driving distance from BUSM. The BU MobileLab helps CityLab to bridge socioeconomic barriers and provides molecular biology lab experiences to diverse, often underserved, populations. Since it hit the road in 1998, the BU MobileLab has served approximately 50,000 students in the greater Boston area and has also been replicated by more than ten mobile science laboratory programs worldwide. The BU MobileLab team also co-founded the Mobile Laboratory Coalition, a professional organization that fosters the growth and development of mobile laboratories for STEM education worldwide.

Pre-Service Science Teacher Education. CityLab's curriculum supplements are used as exemplar lessons for pre-service teachers at SED. In addition, SummerLab hires graduates from SED to serve as educators. The SummerLab educators gain valuable experience teaching hands-on, problem-based investigations in molecular biology and biotechnology to diverse groups of students. Moreover, they take this professional experience with them to their first teaching jobs. Many of these newly-minted science educators return as SummerLab educators and leverage their enduring relationships with CityLab staff as they integrate laboratory-based learning into their own classrooms.

Community Outreach Programs. Over the years, CityLab has offered its laboratory experiences for students from community outreach programs such as the Boston Area Health Education Center, Upward Bound Math and Science, and the National Youth Leadership Forum. CityLab was a core component of BUSM's Mini Med School that teaches adult community members about health and disease. The MobileLab has been featured at BIO national conferences, the USA Science \& Engineering Festival, the Greater Boston Sickle Cell Disease Association's Sickle Cell-a-bration, local scouting events, and many corporate events. These programs introduced political leaders, industry insiders, and the public of all ages to innovative strategies to teach and learn about biotechnology.

CityLab Academy. The success of the BLCS and CityLab programs also led to the development of CityLab Academy (CLA), a nine-month certificate program for high school graduates. With grants from the U.S. Department of Education's FIPSE program, CLA enrolled its first cohort of ten high school graduates in 1996 for a program that consisted of daytime offerings of four BLCS courses. Attending school during the day posed significant financial difficulties for CLA students, since most of them needed to work during the day. These students transitioned into the evening BLCS courses for credit from MET. CityLab Academy grew in popularity due to its rigorous curriculum and strong support services, such as mentoring and job 
placement and acclimation assistance. After the program was established, the CityLab team secured funding to offer the program to both day and evening students. Boston University funded the tuition for CLA students with the hope that the graduates would then continue in the BLCS program and thereby make the investment worthwhile. CLA continued until 2012; more than 100 students graduated with a 12-credit certificate. This credential enabled most CLA graduates to segue into an undergraduate degree program. More than $80 \%$ of CLA graduates went on to secure wellpaid jobs in the biomedical sciences, either in hospitals, university research labs, or biotechnology companies. Once employed, the benefit of employer-funded tuition remission helped students to continue their studies, sometimes onto a $\mathrm{Ph} . \mathrm{D}$. in the biomedical sciences or engineering.

BioScience Academy. As the biotechnology industry began to mature in the $2010 \mathrm{~s}$, the requirements for educational credentials also strengthened. Many local employers required at least a bachelor's degree rather than a certificate for their more desirable positions. To respond to this change in our workforce landscape and with funding from the U.S. Department of Labor, City of Boston, Commonwealth Corporation, and BU, the BioScience Academy (BSA) was established in 2012. BSA recruited unemployed individuals with at least a bachelor's degree who wanted to transition to or become re-employed in the life sciences industry. BSA was a 12-credit, four course, day program with undergraduate-level labs and lecture courses. BSA staff and a strong advisory board comprised mostly of people who were employed in the biotechnology sector provided support services as well as internship and job placement assistance. Fifty-nine students graduated from BSA before it closed in 2017, with more than 50\% securing well-paid jobs in the biotechnology industry. BSA continued the traditions of both BLCS and CityLab by providing current scientific knowledge and skills to students who otherwise would not have had the opportunity to learn about the world of laboratory-based biomedical sciences.

CityLab Satellites. The CityLab model of daily visits and/ or longer-term immersion programs has been replicated at a number of sites in the US and abroad including Beaver Country Day School (MA), Bridgewater State University (MA), UCLA (CA), John Stark High School (NH), Roger Williams Park Zoo (RI), Fountain Hills High School (AZ), University of Strathclyde (Scotland), Washington State University (WA), and University of Texas-Pan American (now University of Texas Rio Grande Valley). While CityLab did not provide financial support to these programs, they received access to CityLab's curriculum supplements. CityLab also shared its expertise with these programs as needed.

\section{SUSTAINABILITY}

Sustainability is a major challenge faced by every grant-funded educational outreach program. After the initial project becomes established, the project's director(s) must maintain what has been developed and still grow the program in new directions in order to remain competitive for public and private extramural funding. CityLab has met this challenge in a variety of ways. CityLab has diversified its funding streams to include a mix of Federal and local grants, corporate and private philanthropic donations, and program-generated revenue. This variety of funding sources has enabled CityLab to continue to offer many of its well-established programs after the end of the funding that facilitated their creation. Table 1 summarizes the major sources of support that led to CityLab's creation and have allowed it to thrive; Figure 1 presents a timeline of major sources of extramural funding from pre-inception to the present.

Since most of CityLab's funding has come from Federal sources, CityLab has developed a culture of perennial innovation. Unlike NIH's T32 pre- and post-doctoral training grants, which are typically renewed based on the number and diversity of the trainees and their scholarly productivity, there is currently no option for renewals of R25 research education grants such as SEPA. Each SEPA R25 application must contain new research questions and/ or develop new programs. SEPA projects such as CityLab can be thought of as training programs cloaked in a research education milieu, since the need to innovate and evaluate is at the core of every science education teaching and learning activity. The R25 structure catalyzes applicants to develop creative ideas that respond to changing technologies and political, social, and cultural mandates as the core elements of each new research education grant application. This structure has also necessitated perennial quests for additional sources of funding to sustain programs that have already been developed, tested, and disseminated; these programs would no longer be seen as innovative and would be unlikely to garner additional SEPA support. CityLab might never have developed such a prodigious array of programs had its leaders not seen this as a means of survival.

CityLab's programs also benefited from NIH's introduction of the multiple principal investigator (MPI) policy in 2006. While CityLab's initial SEPA grants were written with a single PI and several co-Investigators, all of CityLab's NIH grants since 2006 have been written with three PIs under the MPI guidelines. Not only has the MPI policy allowed the three current PIs to develop mutually supportive and complementary expertise, but it has also helped to maintain stable leadership of CityLab. The three PIs are coequal leaders of the SEPA grants who collaborate closely and have developed immense respect for the different talents and contributions that they bring to CityLab's efforts. Having 
three PIs with diverse talents, each of whom contributes only a portion of his/her professional effort to CityLab based on the budgetary requirements of the SEPA program, has enabled CityLab to prosper based on the inherent need for coordination, trust, and interdependence such that any subset of the leaders can assume the responsibilities of the third PI in the event of absence or illness. The NIH's MPI policy and the respective strengths that the three current leaders of CityLab bring to the program are integral to its long-standing impact and innovation.

Adapting CityLab's programming to meet the needs of disparate funders has been a significant challenge. While private philanthropy can be less restrictive than Federal funding, CityLab has only pursued private gifts in specific and well circumscribed cases such as bringing a group of students and teachers from rural North Carolina to SummerLab and funding the initial acquisition and construction of the MobileLab. Private philanthropy, particularly from in-kind gifts, and income generated

Table 1: Major Sources of Funding for CityLab Programs

Grant Funding

Bay State Skills Corporation Grants

US Department of Education - FIPSE Grants

US Department of Education - Eisenhower Grant

US Department of Labor through City of Boston Grant

\section{NIH NCRR/OD/NIGMS SEPA R25 Grants}

NIH NIAAA Alcohol Education Research Education Grant R25

NSF Education and Human Resources - Research in Disabilities Education Grants

Howard Hughes Medical Institute Grants

\section{Institutional Support}

Boston University

\section{Corporate and Philanthropic Support}

Charles Hayden Foundation

Biogen Idec Foundation

Genzyme Foundation

MassBioEd Foundation

Commonwealth Corporation

\section{In-Kind Support}

Lab and office space from BUSM and SED

Equipment and supply donations from BUSM colleagues

Equipment and supply donations from industry - Edvotek

Equipment and supply donations from industry - New England BioLabs

MobileLab renovation - Norfolk Agricultural and Technical High School (MA) from non-grant-funded activities such as SummerLab have provided essential funding to maintain core CityLab programs that were originally developed with SEPA or other Federal support.

CityLab's commitment to equity and access for all students and teachers has also been a key factor in the program's success and sustainability. While "no child left behind" has been part of the national landscape since it was promulgated in 2001 (No Child Left Behind [NCLB], 2002) and subsequently replaced by the "every student succeeds" (Every Student Succeeds Act [ESSA], 2015) mandate, one of CityLab's core missions has been to engage every student and teacher in laboratory-based hands-on biomedical science experiences. CityLab has created programs to promote lab experiences for students with disabilities by training pairs of in-service science and special education teachers in best practices to make this a reality. CityLab also makes nearly all of its programs and resources available at no cost, thereby reducing the economic barriers to access for people or schools of limited economic means. Finally, and perhaps most importantly, the MobileLab has been a vehicle for equity since it gives CityLab the opportunity to bring science to students in myriad urban and rural settings where schools lack the requisite materials and people to allow students and teachers to engage in authentic biotechnology laboratory experiences. CityLab and MobileLab student populations meet or exceed the diversity of the Commonwealth of Massachusetts (Massachusetts Department of Elementary and Secondary Education, 2020) over its existence, with female participants comprising $54 \%$ of the population served and $30 \%$ of the student participants self-identifying as members of underrepresented minority groups.

Without a doubt, the vision to create a diverse biomedical science workforce through CityLab's programming and materials has galvanized and unified CityLab's staff and helped to sustain long-standing partnerships with teachers, schools, and community organizations in the greater Boston area and beyond. In addition to the countless partnerships with individual teachers who have attended professional development workshops, brought their classes to CityLab or welcomed the MobileLab to their campuses, CityLab has built enduring relationships with teachers who spent seminal portions of their early careers as CityLab Educators and then moved on to careers as public, private, or charter school educators. A number of these professional educators return each year as instructors for the SummerLab program. CityLab's leaders have also maintained close ties with a former CityLab Scientist who left BUSM to build a corporate biotechnology teaching lab across the river in Cambridge, MA. These rich and lasting partnerships have been cemented by the positive engagement that CityLab's staff members felt while they worked at CityLab and have also played a key role in CityLab's stability. 


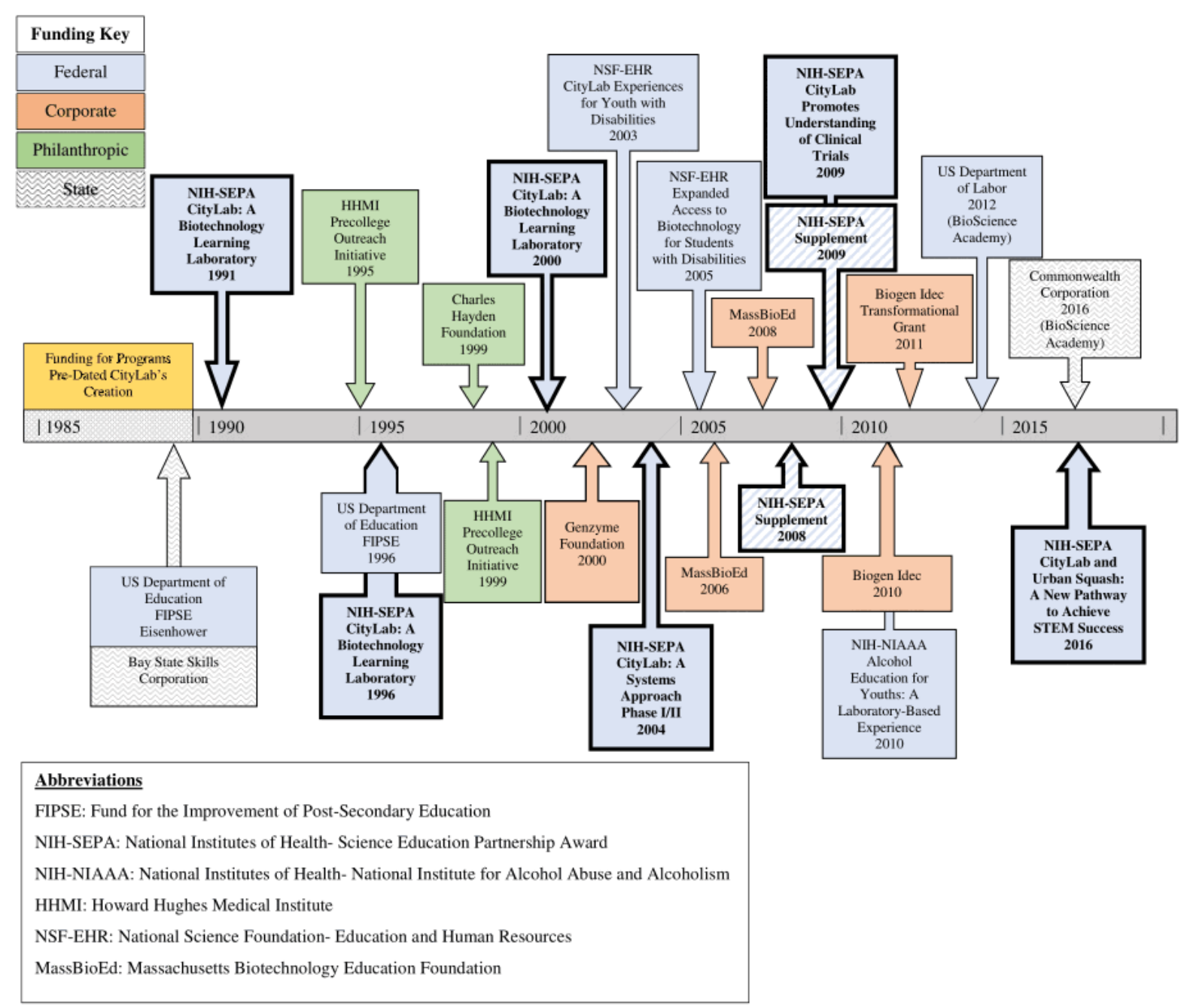

Figure 1. Timeline of Major Funding for CityLab from Extramural Sources

While the aforementioned factors have contributed to CityLab's longevity, perhaps the key factor that has made it possible for the program to thrive for so long is the presence of a powerful, well-connected, and tireless institutional advocate for CityLab. CityLab would never have obtained dedicated teaching labs, classroom space, and offices for staff without a champion who was able to secure these essential resources from BU. CityLab also benefited from creating faculty appointments at BUSM for the leaders of the program since this has contributed to the long-term stability of the leadership team. CityLab's value to BUSM was recognized by the Association of American Medical Colleges in 1995 when it awarded its first national community service award to BUSM and identified CityLab as one of four outstanding programs that led to the award. CityLab's contribution to building a diverse biomedical science workforce of the future would never have been realized had it not been for the mission-driven motivation and zealous commitment of CityLab's founder.

\section{EVALUATION}

CityLab has also embraced program evaluation and assessment as key to long-term viability and sustainability. Over the past thirty years, funders have dramatically increased their attention to evaluation and results. During CityLab's early years, evaluations focused on the number of students and teachers who participated as well as their demographics and reported satisfaction; limited attention was paid to learning outcomes. CityLab augmented these metrics by querying teachers and students about their experiences with CityLab's programs, seeking evidence of learning gains, and monitoring the growth of the wait list to participate in CityLab programs. Over time, requirements for ever more rigorous evaluations have increased and CityLab has responded to these mandates and implemented well matched comparison group studies. Evaluation data help to refine CityLab programs and provide impact data to share with funders. Some key findings from CityLab's evaluations are highlighted below. 
During CityLab's early years, there were limited calls for evaluation and no requirement for dedicated funding for external program evaluators. However, CityLab staff designed and distributed a comprehensive "10th Anniversary Survey" to assess the utility of and satisfaction with CityLab's curriculum supplements, laboratory experiences, and teacher professional development workshops. This survey was mailed to nearly 300 teachers who had visited CityLab or used the MobileLab at least once and 111 surveys were returned, yielding a $37 \%$ response rate. The major findings from this survey are shown in Figures 2A and $2 \mathrm{~B}$. The teachers worked in both public $(83 \%)$ and private schools $(17 \%)$ in a variety of settings, ranging from large urban districts to small rural schools. The range of teaching experience was also extensive- with 75 teachers who had been teaching for more than 10 years. Of the respondents, approximately 50\% had participated in CityLab's programs for four years or longer. Out of 91 respondents, 76 (84\%) indicated that their experience at CityLab affected their teaching in a positive way and $73 \%$ of respondents indicated that CityLab influenced their own curriculum content. Remarkably, $53 \%$ of respondents indicated that aspects of CityLab had been directly incorporated into their curricula. These responses are potent testaments to the impact of CityLab's programs on teachers' practices.

Providing science teachers with biotechnology education has always been an important objective for CityLab, since many schools lack ongoing professional development opportunities and cannot provide access to equipment and laboratories that allow these teachers to more effectively teach their students. To date, more than 2,000 teachers have attended CityLab teacher professional development workshops and over 100 pre-service teachers have learned CityLab's curricula and pedagogy though a science methods course at SED.

In a similar vein, the results of a survey of MobileLab users in 2011 suggested that science teachers perceived an overall positive impact of mobile laboratory programs on science education. These perceptions were validated by the relatively strong desire to be repeat users of the mobile laboratory programs $(85 \%$ rating $\geq 5$ on a 6-point Likerttype scale running from $1=$ most negative to $6=$ most positive). The impact of a mobile laboratory program on science education was well captured by a teacher's comment on the survey:

\section{With our school and schools in general in a budgetary crisis, field trips are out of the question. The [mobile laboratory] provides quality enrichment activities without the cost of taking students off site. The value of this experience is immeasurable when you consider the number of students who are able to participate. Of those, many were inspired to explore science as a career. The spark that an opportunity like this is able to give a class is not easily duplicated (Franzblau et al., 2011).}

CityLab has also undertaken evaluation of the impact of the SummerLab program, but the evaluations have specifically focused on gains in students' content knowledge and their understanding of scientific inquiry. Pre- and posttests were administered that were designed to assess students' understanding at nominal, functional, and structural levels of biological literacy, where nominal literacy is characterized by identifying terms and concepts, functional literacy is described as the correct use of biological vocabulary and definitions, and structural literacy is characterized by the ability to explain biological concepts in one's own words (Biological Sciences Curriculum Studies, 1993). In addition to the pre- and post-content tests, post-experience focus groups were held to obtain student feedback.

The pre- and post-tests consisted of sixteen multiple choice questions and five open response questions. The multiple choice questions served as an indicator of nominal literacy, while three open response questions reflected functional literacy and the final two open response questions

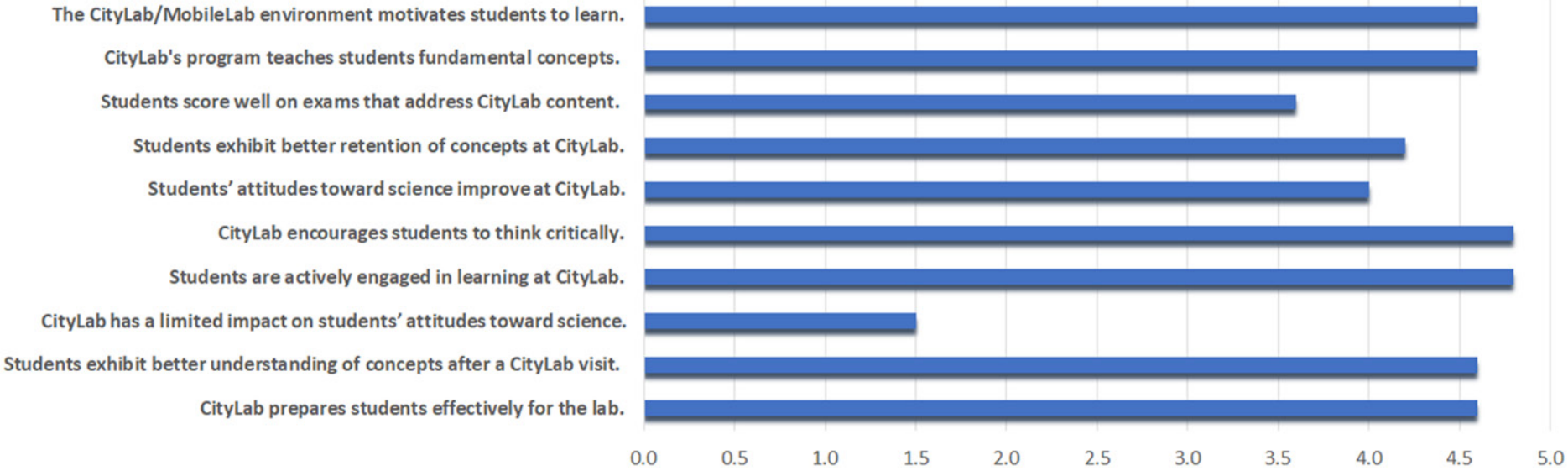

Figure 2A. Responses to CityLab's 10th Anniversary Survey. Teacher Reports of Student Impact. 


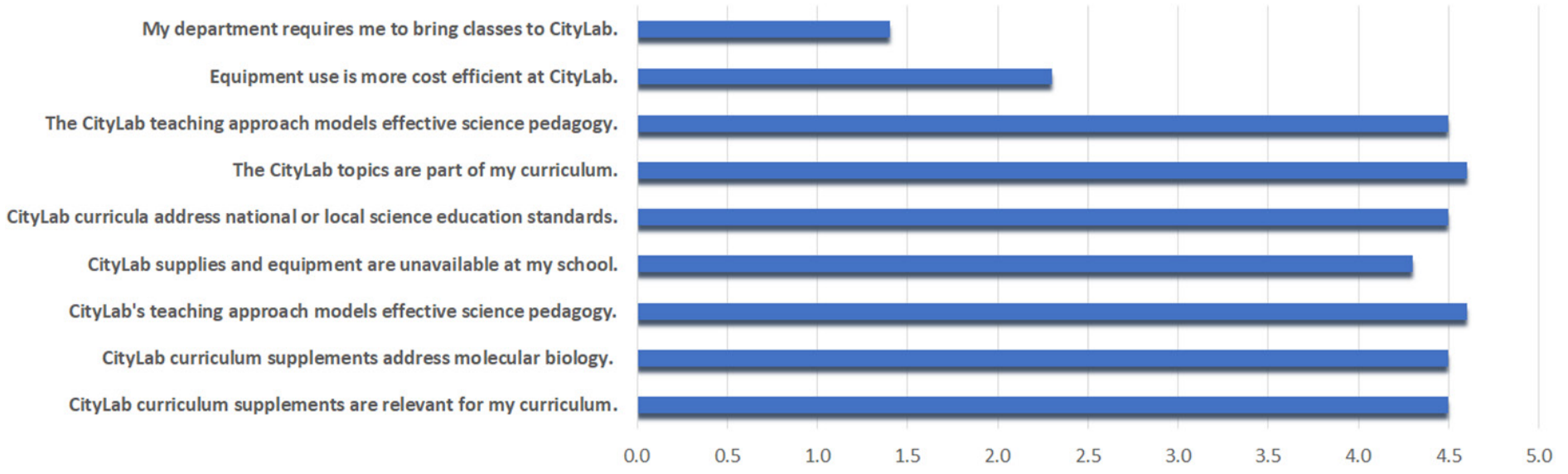

Figure 2B. Responses to CityLab's 10th Anniversary Survey. Teacher Self-Report.

addressed structural literacy. Hake gain scores were used to measure the average normalized gain $\langle\mathrm{g}\rangle$, defined as the ratio of the actual average gain $<\mathrm{G}>$ to the maximum possible average gain, i.e., $<\mathrm{g}>=\%<\mathrm{G}>/ \%<\mathrm{G}>\max =$ $(\%<\mathrm{Sf}>-\%<\mathrm{Si}>) /(100-\%<\mathrm{Si}>)$, where $<\mathrm{Sf}>$ and $<\mathrm{Si}>$ are the final (post) and initial (pre) class averages (Hake, 1998). Hake gain scores are considered to be low when the $<\mathrm{g}>$ is below 0.3 , medium when $\langle\mathrm{g}>$ is between 0.3 and 0.7 , and high when $<\mathrm{g}>$ is above 0.7 . The Hake gain for students in the SummerLab program $(\mathrm{N}=91)$ is 0.52 , suggesting that SummerLab students make medium gains in their advancement of content understanding.

Student focus groups revealed that students wanted more laboratory experience (approximately 50-60\% of the SummerLab experience was spent in the laboratory). In particular, students enjoyed the opportunities to modify laboratory techniques and design their own investigations and experiments.

Formal evaluation of learning gains and program effectiveness have become more rigorous since the 1990s, but informal and anecdotal evidence of CityLab's impact on students, teachers, and the community are powerful testaments to its enduring value. The waiting lists and high percentage of teachers who consistently bring their classes to CityLab or use the MobileLab are important indicators that teachers want and need this resource. The widespread use of CityLab's curriculum supplements, with dissemination directly to thousands of teachers who have downloaded the manuals or purchased kits, also demonstrates teachers' interest in implementing CityLab's laboratory experiences in their own classrooms. Moreover, the successful adoption of the CityLab and MobileLab models of daily visits, in-depth immersion programs, and mobile science laboratories by other groups in US and elsewhere shows that these programs are replicable and can be adapted to meet local needs. To date, well over one million people have participated in a laboratory-based biomedical science experience that emanated from the BU team and untold students have engaged in authentic scientific inquiry that may have inspired them to careers in STEM fields. Even though specific quantification of these impacts is impossible, the propagation of CityLab's conceptual structures is a powerful indicator of its success in realizing its mission.

\section{DISCUSSION AND CONCLUSION}

CityLab's success is a testament to visionary leadership that recognizes and responds to urgent local and national needs to build a biomedical sciences workforce. CityLab has flourished as an educational outreach program for thirty years through active dissemination, strong scientist-educator partnerships, and diverse funding streams. The narrative above, however, does not do justice to the challenges that CityLab has faced and strives to address. Science education outreach programs such as CityLab are particularly vulnerable now since there is diminished attention to science and education in the national arena (Anderson, 2012). CityLab and similar pre-college STEM education outreach programs may not be able to sustain themselves without some bold new ideas to alleviate the challenges of sustaining programs. One possible strategy involves re-envisioning some Federal STEM research education grants as precollege training grants that would be eligible for competitive renewal based on accomplishments in developing innovative materials or working with underserved populations and advancing their science knowledge and skills. The training grants could be modeled on the NIH T32 model, with opportunities to compete for renewal of funding to support on-going programming and large-scale dissemination efforts to expand the reach of successful innovations and programs.

A second strategy involves raising the budget caps on Federal STEM education grants so that programs have adequate funding to undertake their work. SEPA is but one example of a program that had higher annual direct costs in 2000 than today (National Institutes of Health 2000, 2005, 2017). In 2000, the maximum annual direct costs for a SEPA 
grant were $\$ 300,000$ and in 2005 the cap was reduced to $\$ 250,000$; it remains at $\$ 250,000$ today. Using Federal data, an annual direct cost cap of $\$ 456,707$ in December, 2019 would have equivalent purchasing power to that which was available to SEPA grantees in January 2000 (U.S. Bureau of Labor Statistics, 2020). Since effective STEM education has been and will continue to be an important U.S. strategic need (National Science Board, 2018; Rutherford et al., 1989), providing adequate funding to investigators and projects through SEPA and other similar NIH R25 programs is essential.

Despite challenging economic and political realities as it enters its fourth decade, CityLab holds fast to its commitment to be an innovative force in making biomedical science education available and accessible to all.

\section{AUTHOR INFORMATION \\ Corresponding Author}

Dr. Carla Romney. Boston University School of Medicine, 72 E. Concord Street, A5, Boston, MA 02118. (617) 3582161.romney@bu.edu.

\section{Author Contributions}

The manuscript was written through contributions of all authors. All authors have given approval to the final version of the manuscript.

\section{ACKNOWLEDGMENTS}

The authors gratefully acknowledge the untold contributions of the students and teachers who have used CityLab materials and offered feedback to guide their development and refinement. CityLab's evaluators, especially Dr. Russell Faux of Davis Square Research Associates, have led the effort to assess the impact of CityLab's programs and the authors appreciate the thoughtful insights that have emanated from project and program evaluations. Finally, the authors are indebted to the educators, scientists, and program administrators who have made a shared vision into a reality for the thousands of people who have participated in a CityLab experience.

\section{FUNDING SOURCE}

Research reported in this publication was supported by the National Institute of General Medical Sciences of the National Institutes of Health under Award Number R25GM129205. The content is solely the responsibility of the authors and does not necessarily represent the official views of the National Institutes of Health.

\section{ABBREVIATIONS}

BIO: Biotechnology Industry Organization (now known as Biotechnology Innovation Organization); BLCS: Biomedical Laboratory and Clinical Sciences; BSA: BioScience Academy; BU: Boston University; BUSM: Boston University School of Medicine; CLA: CityLab Academy; ESSA: Every Student Succeeds Act; FIPSE: Fund for the Improvement of Post-Secondary Education; MET: Metropolitan College; MPI: Multiple Principal Investigator; NCLB: No Child Left Behind; NCRR: National Center for Research Resources; NIH: National Institutes of Health; SED: Boston University School of Education (now known as Boston University Wheelock College of Education and Human Development); SEPA: Science Education Partnership Award; STEM: Science, Technology, Engineering, and Mathematics.

\section{REFERENCES}

Anderson, K. J. B. (2012). Science education and test-based accountability: Reviewing their relationship and exploring implications for future policy. Science Education, 96(1), 104-129. Retrieved from https://doi.org/10.1002/ sce. 20464 .

Biological Sciences Curriculum Studies. (1993). Developing biological literacy: a guide to developing secondary and post-secondary biology curricula. Iowa: Kendall Hunt.

Boston University CityLab. (1998). SummerLab curricula. Retrieved from http://www.bumc.bu.edu/citylab/summerlab/ curriculum/.

DeRosa, D.A., and Wolfe, B.L. (1993a). The mystery of the crooked cell. Retrieved from http://www.bumc.bu.edu/citylab/ curriculum/the-mystery-of-the-crooked-cell/.

DeRosa, D.A., and Wolfe, B.L. (1993b). The case of the crown jewels. Retrieved from http://www.bumc.bu.edu/citylab/ curriculum/the-case-of-the-crown-jewels/.

DeRosa, D.A., and Wolfe, B.L. (1993c). Crucial concentration. Retrieved from http://www.bumc.bu.edu/citylab/curriculum/crucial-concentration/.

DeRosa, D.A., and Wolfe, B.L. (1994). Amp up your DNA. Retrieved from http://www.bumc.bu.edu/citylab/curriculum/ amp-up-your-dna/.

DeRosa, D. A., and Wolfe, B. L. (1999). Mystery of the crooked cell: an investigation and laboratory activity about sickle-cell anemia. The American Biology Teacher, 61(2), 137-148. Retrieved from https://doi.org/10.2307/4450635.

Every Student Succeeds Act of 2015, P.L 114-95, 20 USC $\S 6301$ (2015). Retrieved from https://www.congress.gov/114/ plaws/pub195/PLAW-114pub195.pdf. 
Franzblau, C., Romney, C.A., Faux, R., and DeRosa, D. (2011). Mobile laboratory programs as vehicles to promote STEM education in K-12 and beyond. Proceedings of the 41st Frontiers in Education Conference. Retrieved from https:// doi.org/10.1109/FIE.2011.6142774.

Hake, R.R. (1998). Interactive-engagement versus traditional methods: A six-thousand-student survey of mechanics test data for introductory physics courses. American Journal of Physics 66, 64. Retrieved from https://doi. org/10.1119/1.18809.

Massachusetts Department of Elementary and Secondary Education (2020). Information Services. Retrieved from http:// www.doe.mass.edu/infoservices/reports/enroll/.

National Institutes of Health (2000). Science education partnership award. Retrieved from https://grants.nih.gov/grants/ guide/pa-files/PAR-00-036.html.

National Institutes of Health (2005). NCRR Science education partnership award. Retrieved from https:/grants.nih.gov/ grants/guide/pa-files/PAR-05-068.html.

National Institutes of Health (2017). Science education partnership award. Retrieved from https:/grants.nih.gov/grants/ guide/pa-files/PAR-17-339.html.

National Research Council (2006). America's Lab Report: Investigations in High School Science. Washington, DC: The National Academies Press. Retrieved from https://doi. org/10.17226/11311.

National Research Council (2007). Taking Science to School: Learning and Teaching Science in Grades K-8. Washington, DC: The National Academies Press. Retrieved from https://doi.org/10.17226/11625.

National Science Board (2018). Our Nation's Future Competitiveness Relies on Building a STEM-Capable U.S. Workforce: A Policy Companion Statement to Science and Engineering Indicators 2018. Arlington, VA: National Science Foundation.

No Child Left Behind Act of 2001, P.L. 107-110, 20 U.S.C. $§ 6319$ (2002). Retrieved from https://www2.ed.gov/policy/elsec/ leg/esea02/107-110.pdf.

Rutherford, F.J., and Ahlgren, A. (1989). Project 2061 (American Association for the Advancement of Science), Science for All Americans. New York: Oxford University Press. Retrieved from https://www.project2061.org/publications/ sfaa/online/chap14.htm.

Sherr, D., DeRosa, D.A., and Wolfe, B.L. (1993). In search of the body's antibodies. Retrieved from http://www.bumc. bu.edu/citylab/curriculum/in-search-of-the-bodys-antibodies/.

Topalian, N., DeRosa, D.A., and Wolfe, B.L. (1995). Medicine in the new millennium (bacterial transformation). Retrieved from http://www.bumc.bu.edu/citylab/curriculum/medicine-in-the-new-millennium-bacterial-transformation/.
U.S. Bureau of Labor Statistics (2020). CPI inflation calculator. Retrieved from https://www.bls.gov/data/inflation_calculator.htm.

Watanabe, T. (2011). California teachers lack the resources and time to teach science. Los Angeles Times (October 31, 2011). Retrieved from https://www.latimes.com/la-xpm2011-oct-31-la-me-science-20111031-story.html.es. PLoS Biology 17(1): e3000103. 